This article was downloaded by: [New York University]

On: 08 February 2015, At: 11:49

Publisher: Routledge

Informa Ltd Registered in England and Wales Registered Number: 1072954

Registered office: Mortimer House, 37-41 Mortimer Street, London W1T

3J H, UK

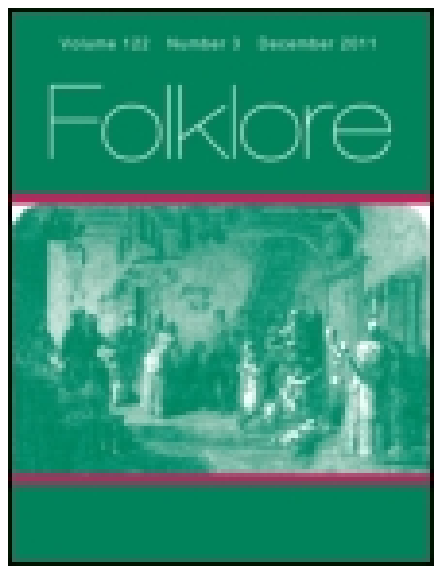

\title{
Folklore
}

Publication details, including instructions for authors and subscription information:

http:// www. tandfonline.com/loi/ rfol20

\section{Annual Address by the President}

G. L. Gomme

Published online: 14 Feb 2012.

To cite this article: G. L. Gomme (1893) Annual Address by the President, Folklore, 4:1, 1-26, DOI: 10.1080/ 0015587X.1893.9720135

To link to this article: http:// dx. doi.org/ 10.1080/0015587X. 1893.9720135

\section{PLEASE SCROLL DOWN FOR ARTICLE}

Taylor \& Francis makes every effort to ensure the accuracy of all the information (the "Content") contained in the publications on our platform. However, Taylor \& Francis, our agents, and our licensors make no representations or warranties whatsoever as to the accuracy, completeness, or suitability for any purpose of the Content. Any opinions and views expressed in this publication are the opinions and views of the authors, and are not the views of or endorsed by Taylor \& Francis. The accuracy of the Content should not be relied upon and should be independently verified with primary sources of information. Taylor and Francis shall not be liable for any losses, actions, claims, proceedings, demands, costs, expenses, damages, and other liabilities whatsoever or howsoever caused arising directly or indirectly in connection with, in relation to or arising out of the use of the Content.

This article may be used for research, teaching, and private study purposes. Any substantial or systematic reproduction, redistribution, reselling, loan, sub-licensing, systematic supply, or distribution in any form to anyone is 
expressly forbidden. Terms $\&$ Conditions of access and use can be found at http://www.tandfonline.com/page/terms-and-conditions 


\section{$\mathfrak{J f o l k}=$ Wore.}

\begin{tabular}{lll}
\hline VOL IV.] & MARCH, 1893. \\
\hline
\end{tabular}

\section{ANNUAL ADDRESS BY THE PRESIDENT.}

I ADIES AND GENTLEMEN,-I have the honour L to address you a second time from this chair-an honour I feel all the more keenly because I really did not anticipate being asked to keep better men out of it any longer, and because there is so much evidence that the Society is taking year by year a more prominent place among learned bodies.

My duty is to survey our last year's work, and that is as difficult as it is pleasing. By this I mean to say that so much good work has been accomplished, that it is really no easy task to summarișe it satisfactorily, partly on account of its magnitude, partly on account of its excellence. The papers of the session and the publications are duly set forth in the annual report, though, personally, I demur to the classification there adopted, which appears to relegate to a minor order of importance papers which are short as distinguished from those that are long.

Most of the papers have been published in the Society's official organ, FOLK-LORE, while some have found a home elsewhere. It is a noteworthy fact that more attention has been paid this year to custom and belief than has hitherto been the case; and, as this has been my own especial department of inquiry, I cannot help expressing my pleasure. at it-a pleasure, however, damped to a considerable degree

vol. Iv.

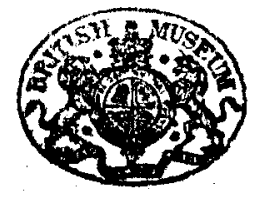


by the fact that for the second year we have missed one of those brilliant studies we were accustomed to look for from our Treasurer, Mr. Edward Clodd, and for the first time, I think, we have not been favoured by Mr. Alfred Nutt. We have not adopted the practice of taking down our discussions, or allowing speakers to transcribe for us afterwards the observations they made upon the papers; and I think this is a matter that we might very well improve upon, because I bear in mind one or two occasions where facts were mentioned by members or their friends which were of some moment. A new feature of the past year. has been the exhibition of folk-lore objects at our meetings, and there can be no doubt that this is a highly desirable part of our proceedings, to which we might perhaps pay somewhat more attention. Furthermore, the claims we have upon amateur photographers have been clearly put forward by Mr. Ordish, and most significantly illustrated by Professor Haddon, whose marriage-masks from County Mayo are about the most curious things we have yet had brought to our notice. There arc numbers of other things to photograph, and I hope during the coming year we may be able to form an album of photographs which might be placed upon the table at each of our meetings. We are not in the habit of proposing votes of thanks to the readers of papers at our meetings ; indeed, our expressions of thankfulness are singularly few, and in this respect we depart from the custom of our compeers. I suppose it is that our subject is sufficient return for labour, and because, when Mr. Hartland gives us a brilliant study, when $\mathrm{Mr}$. Billson comes forward for the first time to show that the cause is extending, when Professor Rhys gives us what he is pleased to call "Stray Notes", we get exactly what we are accustomed to expect from these scholars, and our thanks die away with the fascination of the subject. None the less, however, we are indebted to those members who give us the result of their labours, and personally I am greatly obliged that they should have 
signalised my term of office by such sound contributions to our science.

If I attempt to sum up in one sentence what, so far as I have been able to interpret it, is the chief lesson to be drawn from the past year's work of our Society, and of folk-lore studies generally, I should unhesitatingly affirm it to be the need for formulating the principles of the science of Folk-lore. Once more there is a move forward, and our Society, in this case as in previous departures in the methods of studying folk-lore, takes the lead.

I want to lay a little stress upon this, because it really is so important for our future progress. I will accordingly very briefly note what strikes me as the principles of folklore which have been discussed during the past year. It may be, of course, that some of our decisions will have to be surrendered as our science develops, nay, that all of them will have to be surrendered. But of one thing I am quite certain : no true progress can be made unless these principles are set forth and discussed, and if they serve simply as the stepping-stones to the discovery of a Grimm's Law in folk-lore, as last year I ventured to call it, I for one shall be very glad to surrender them to that use, and to be proud if I should happen to have provided one of such stepping-stones.

The first principle, then, which appears to me to have been established is that folk-lore must be studied item by item in its own home, before it can properly be applied to other uses demanded by the comparative method of scientific inquiry. This principle has been asserted practically, if not in terms, by three different authorities, and quite independently of each other-by Mr. Abercromby in his paper on "Finnish Origins", read at one of our meetings ; by Mr. Karl Krohn in a valuable paper on the "Geographical Distribution of Esthonian Songs", and by myself in my "Ethnology in Folk-lore". Each item of folk-lore has a biography which must be written. It may happen, if we are ignorant of this biography, that we get hold of a parti- 
cular item, and in the single form in which it has come to hand, we proceed to use it in comparison with some foreig parallel or with some savage parallel. But that comparison must be imperfect unless we know that the example is in fact the most perfect survival of the original that is to be found. Its relationship to other examples of the samg species must be carefully traced out, and the particulat evidence which that relationship brings out must be taken into account. The work here indicated is a laborious one and a lengthy one, but, being necessary and being scientific. it is a work which I would urge the Society in every way to encourage, if not to actually commence undertaking it for our own country.

The second principle, which I think flows from the first. is what I would call the measurement of the survival. To some extent I indicated this also in my little book already referred to ; but it is to $\mathrm{Mr}$. Abcicromby that we owe clear pronouncement on the subject. "Though the word survival", says Mr. Abercromby, "strictly connotes the notion of uninterrupted continuity between its extreme terms it does not involve any exact notion of length. Sur vivals may therefore be of different lengths or ages. If $a$ line $A Z$ be taken to represent the earliest possible surviva down to the present time, then $F Z, S Z, v Z$ will represen shorter ones, the alphabetical distance of $F \mathrm{~S}$ and showing their relative distances from that point." Thes are weighty words, and they formulate a principle whick though existing in many of our minds, has not yet beed actually set forth and expressed. I would, however venture to make an amendment upon Mr. Abercromby's plan. I would use figures up to a hundred, instead of the alphabet; and then our measurer would assume some what the form of a barometer, the several stages being marked according to the circumstances of each country So that Mr. Abercromby's suggestion may not fall idly by I have ventured to construct, for the purpose of criticism what we might call the British measurement of the survival 
and I hope our Council will take it up and see if, by our united wisdom, we cannot definitely fix upon the range and terms to be used. It would present to the folk-lore student a guide something like the anthropometrical standards have supplied to craniological students, and other countries may follow our example and construct for themselves their own measurer of survivals.

It is a magnificent contemplation that we may begin to measure our items of folk-lore; to trace some up to the mediæval monastery or manorial lord, others to the paganism of Scandinavians, or Teutons, others to the paganism of the Celts, others to a savagery which falls into no historical chronology at present. And then to examine the residue and endeavour to work out by analogy and comparison their place in the system. There would be such a clearance of the unclassified items of folk-lore that we could hope to see some way out of the immense difficulties all must feel in the present chaos of materials, and we could begin to sum up the worthless items.

Now, at present, it is an extremely dangerous proceeding to suggest that folk-lore possesses any worthless items. At all events I am not prepared to give a catalogue of them; and I have rescued several apparently worthless fragments from oblivion, though it was impossible to say what their value is. For instance, my friend $\mathrm{Mr}$. Rackham Mann, of Shropham in Norfolk, not long since told me that the farming peasantry of his neighbourhood always throw the afterbirth of sheep into the trees; and during lambing time the trees are to be seen everywhere bedecked with these not particularly pleasing trophies. Now is this custom worthless or not as an item of folk-lore? First, then, we note that it is commonly believed if the performance were not gone through ill-luck would attend the flock. Secondly, by searching for other examples of the group to which it belongs, we come upon the most perfect form in the series of gradations which it presents, namely, the Sussex practice, noted by Mr. Baring Gould, of hanging 
up dead horses or calves by the four legs to the horizontal branch of a tree. It is a sufficiently ghastly sight; and one spring Mr. Baring Gould saw two horses and three calves hanging on a magnificent elm in Westmeston, just under the Ditchling beacon. Here, too, the reason for the custom is that it was thought lucky for the cattle. What, then, is the measurement of this survival? We have it on the authority of Tacitus that the ancient Germanic tribes hung the heads of horses upon trees as offerings to Odin; and after the overthrow of Varus, in A.D. I5, the scene was enlivened by examples of this practice. This is the pagan parallel to the survival. The clear connection between the form of sacrifice, namely, the offering on the tree, in both the ancient and modern practice, obviates the necessity for seeking further; and we are justified in concluding that the peasantry of. Norfolk, Sussex, and other parts of England have kept for at least ten centuries the practices which their forefathers religiously held to be necessary to their soul's salvation.

Will anyone say that we have not measured this survival correctly? I think not, and, when one considers the enormous number of survivals that need to undergo this process, the sooner we put the measuring instrument to use the better. We get no nearer the truth by simply calling such customs "survivals"-survivals of what, is the real question; and when this has been answered with reference to the bulk of our folk-lore, then we may begin to discuss the question of origins.

The next principle is that folk-lore cannot by any possibility develop: The doctrine of evolution is so strong upon us that we are apt to apply its leading idea insensibly to almost every branch of human history. But folk-lore, being what it is, namely, the survival of traditional ideas or practices among a people whose principal members have passed beyond the stage of civilisation which those ideas and practices once represented, it is impossible for it to have any development. When the original ideas and practices which 
it represents were current as the standard form of culture, their future history was then to be looked for along the lines of development. But so soon as they dropped back behind the standard of culture, whatever the cause and whenever the event happened, then their future history could only be traced along the lines of decay and disintegration. We are acquainted with some of the laws which mark the development of primitive culture, but we know nothing of the influences which mark the existence of survivals in culture. For this purpose we must be carcful to ascertain what are the component parts of each myth, custom, or superstition. These will be found to consist of three distinct elements, which I would distinguish by the following names:-

(1) The formula.

(2) The purpose.

(3) The penalty or result.

I am going for a moment to be a little technical, but it is necessary. This dissecting analysis of folk-lore is very important for the right interpretation of the meaning to be given to the item undergoing analysis; for these three component parts are not equally tenacious of their original form in all examples. In one example we may find the formula cither actually or symbolically perfect, while the purpose and the penalty may not exist. In another example the formula may be less perfect, while the purpose and penalty may be distinguishable easily. Or it may happen that the formula remains fairly perfect; the purpose may be set down to the desire of doing what has always been done, and the penalty may be given as luck or ill-luck. Of course, further variations are possible, but these are usually the more general forms.

I will give an example or two of these phases of change or degradation in folk-lore. First, then, where the formula is complete, or nearly so, and the purpose and penalty have both ;disappeared. At Carrickfergus it was formerly the 
custom for mothers, when giving their child the breast for the last time, to put an egg in its hand and sit on the threshold of the outer door with a leg on each side, and this ceremony was usually done on a Sunday. Undoubtedly I think we have here a very nearly perfect formula; but what is its purpose, and what is the penalty for non-observance? Upon both these latter points the example is silent, and before they can be restored we must search among the other fragments of threshold customs and see whether they exist either separately from the formula or with a less perfect example.

The second phase of the analysis, where the formula has disappeared and the purpose and penalty remain, covers nearly the whole range of those floating beliefs and superstitions which occupy so largely the collections of folk-lore. But I will select one example which will be to the point. When the Manx cottager looks for the traces of a foot in the ashes of his firegrate for the purpose of seeing in what direction the toes point, the penalty being that, if they point to the door, a death will occur, if to the fireplace, a birth, there is no trace of the ancient formula. It is true we may find the missing formula in other lands, for instance, among some of the Indian tribes of Bombay. There the formula is elaborate and complete, while the purpose and the penalty are exactly the same as in the Isle of Man. But this hasty travelling to other lands is not, I contend, legitimate in the first place. We must begin by seeing whether there is not some other item of folk-lore, perhaps not now even connected with the house-fire group of customs and superstitions, whose true place is that of the lost formula of this interesting Manx custom. And when once we have taught ourselves the way to restore these lost formulæ to their rightful places, I put it to you whether the explanation of the mere waifs and strays of folk-lore, will not be attended with some approach to -scientific accuracy, and whether we shall not then be in a position to get rid of that shibboleth so dear to the non- 
folklore critic, that all these things we deal with are " mere superstitions".

Thirdly, when the formula is complete, or nearly so, and the purpose and penalty become generalised. At St. Edmundsbury a white bull, which enjoyed full ease and plenty in the fields, and was never yoked to the plough or employed in any service, was led in procession through the chief streets of the town to the principal gate of the monastery, attended by all the monks singing and a shouting crowd. Knowing what Grimm has collected concerning the worship of the white bull, knowing what is performed in India to this day, there is no doubt that this formula of the white bull at St. Edmundsbury has been preserved in very good condition. The purpose of it was, however, not so satisfactory. It is said to have taken place whenever a married woman wished to have a child ; and the penalty is lost in the obvious generalisation that not to perform the ceremony is not to obtain the desired end.

In these cases we have before us examples of the changes in folk-lore, and demonstrably they are changes of decay, not of development. By grouping them and arranging them it may be possible to ascertain and set down the laws of change-for that there are laws I am nearly certain, just as there are laws for word-change. It is these laws which must be discovered before we can go very far forward in our studies. Every item of custom and superstition must be tested by analysis to find out under which power it lives on in survival, and, according to the result in each case, so may we hope to find out something about the story which folk-lore has to tell us of ancient man.

The next principle relates to the causes of the continuation of folk-lore. And herein is one of our greatest problems. A custom, belief, or superstition is continued year after year, when it is barbarous, sometimes indecent, oftentimes disgusting or brutally cruel ; a legend, or myth, is related 
from one generation to another, when its central idea is cannibalism, incest, or impossible theories about life or the soul of man.

The determination of this principle rests upon the problem of continuity. There is and can be no proof of continuity from a prehistoric savagery to a survival of savagery amidst civilisation, and the theory of continuity is therefore the most open to attack and to divergency of opinions. At present the position of opinion on this point may be summed up somewhat as follows :-

(I) The continuity of custom, belief, or superstition may be due, first, to the continuity of the people with whom originated the custom, belief, or superstition, such people being isolated, and generally considered as outcasts by the more cultured people; secondly, to the generation of custom, belief, or superstition of the same kind by people at the same level of mental development, wherever they may be existing, or at whatever date.

(2) The continuity of legend or myth is due, first, to the continuity of the belief which generates the legend or myth ; secondly, to the adaptation by a people of a myth which supplied them with an explanation of some phenomenon that they could not explain themselves; thirdly, to the influence unconsciously exercised by the art born of the countless tongues who have told these legends so faithfully and so long; fourthly, to the same cause as that already noted under custom, namely, the generation of the same thought by people of the same mental development, wherever they may be existing, or at whatever date.

I think I have stated the case fairly. It will be seen by examination that the factors in both these classes of folklore-custom and myth-are practically the same, with one exception, namely, the influence of the art exercised by the fairy-tale independently of its origin.

Now, to every school of folk-lore thought this art must be admitted to be a growth of civilisation, using that word, of course, in its widest sense. So I leave this element 
alone, and proceed to examine the other elements in connection with this part of our subject.

Let us subtract scientific knowledge from our present conception of nature, and what remains to us but the story of Adam and Eve and the first chapter of Genesis? These have satisfied whole generations of our forefathers, amply satisfied them, simply because there was nothing to takc their place, and because they were propounded from the pulpit, the college chair, and the schools. But the wide and universal acceptance of such a conception of natural causes is due to an important factor in the problem we are discussing, namely, the generation of similar beliefs by people at the same level of culture. If this particular form of belief had not been supplied from foreign sources, it would have been found that some other general form of belief would have been supplied from a native source; for, in the words of Mr. Clodd's eloquent apology for not including detailed references to the successive stages of the inquiry into myth', "the list of ancient and modern vagaries would have the monotony of a catalogue, for, however unlike on the surface, they are fundamentally the same.' Therefore, the acceptance of an outside myth by a people could never happen if such a myth did not meet a perfectly even surface of mental culture upon which to build its home. It is simply the converse of the more generally stated proposition that like conditions would generate like beliefs, and as such it helps to prove the truth of its reverse.

There is one other aspect of this branch of our subject which I want to note, because it has been attacked during the past year as almost an impossibility. Finding that in India a group of customs, peculiarly savage and at a low level of culture, obtains in Aryan villages, but at the instance and under the guidance of non-Aryan inhabitants, we have an example of the Aryans accepting this villagefestival as a part of the religious duties of the season borrowed from the indigenes of the land. Whether the 
borrowing was a self-imposed act undertaken in obedience to their own ideas and conceptions of the necessities of the case, or whether it was the result of a forced acceptance in order to conciliate the conquered indigenes, need not be discussed at this stage; but there is not wanting evidence that the latter of the two contingencies may be accepted as the true interpretation of the events.

I think we are now in touch with a theory which has been formulated by folk-lore students, and which is known as the "borrowing theory". This has long been rejected by those who cannot accept as evidence the somewhat plausible statements which have from time to time been put forward, that the likeness so noticeable in the folk-lore of widely separated countries is due to a conscious borrowing from a common centre. And in its place has been set up the theory that the savage elements in folk-lore are but the originals from which the developed elements have been derived. To meet this view, it is necessary to assume that primitive Aryan conceptions have grown up in several independent places, and did not come from a common home. The difficulties in the way of accepting this explanation are many, and so the existence of a primitive Aryan race has been called into question. As Professor Rhys, not long since, wrote to me, because there are too many Aryans now to suit the researches of specialists, the conclusion they would draw is that there were originally none at all. But if the preservation of rude and savage custom side by side with higher Aryan thought is proved, by the evidence which has just been noted, to have been brought about by the preservation of the race with whom such custom originated, and by the adoption of it by the race who appear in history as conquerors, we may accept this borrowing theory as sufficient to account for many apparent anomalies in folk-lore. We shall have to push back the date when a people can with any plausibility be said to borrow its folk-lore to the period when that people first settled in its present home as conquerors. We shall 
have to be careful in our application of the term "borrowers". These are not the peasant-class of modern Europe who have succeeded to the uncivilisation of the indigenous populations. The borrowers are those races who appear as conquerors, and who adopted and adapted some of the beliefs of the indigenes among whom they settled. It is a fact, says Dalton, that while the mass of the Kols have not taken to the worship of any Hindoo idols, the Hindoos settled in the province think it expedient to propitiate the gods of the Kols. When the Gaulish cohort erected an altar on the limits of Caledonia, dedicated to the field-deities and deities of Britain, he was borrowing from the beliefs of the Britons-the incomer borrowing from the indigenous dweller-and this was a practice sanctioned by the religious principles of Greece and Rome. In point of fact, borrowing in folk-lore is an ethnic process, not an historical one, and it most be studied from that point of view.

If this helps to explain the borrowing theory-and except for modern days I think it does-we may turn for one moment to the casualistic theory, as $\mathrm{Mr}$. Jacobs in his scorn has called it. It is important to bear this in mind, because its leading facts and influences are being so constantly overlooked, or narrowed down into an impossibly small compass when dealing with survivals with reference to their origin. There is no excuse for such forgetfulness when the most important of all the evidence has been so clearly set forth from the ascertained facts of gesture-language by " a man called Tylor", as Rudyard Kipling might put it into the mouth of a folk-lorist who is perpetually forgetting his masters in the science. I allude to this part of our subject the more particularly, because in the discussion which followed Mr. Stuart-Glennie's extremely suggestive code of queries on animism, I remember the subject came to the fore.

I first turn to custom. Near Inverary, it is the custom among the fisher-folk, and has been so within the memory 
of the oldest, to place little white stones or pebbles on the graves of their friends. No reason is now given for the practice, beyond that most potent and delightful of all reasons in the minds of folk-lore students, namely, that it has always been done. Now there is nothing between this modern practice sanctioned by traditional observance and the practice of the stone-age people in the same neighbourhood and in others, as made known to us by their graverelics. Thus, in a cairn at Achnacrie opencd by Dr. Angus Smith, on entering the innermost chamber " the first thing that struck the eye was a row of quartz pebbles larger than a walnut; these were arranged on the ledge of the lower granite block of the east side." Near Crinan, at Duncraigaig and at Rudie, the same characteristic was observed, and Canon Greenwell, who examined the cairns, says the pebbles "must have been placed there with some intention, and probably possessed a symbolic meaning".

If the modern practice is a survival of the stonc-age practice, the measurement of the survival is one of the hundredth power, if I may use the "measurer" I have suggested. But, in the absence of information about the symbolic meaning of the white pebble, this measurement cannot be accepted with certainty; and the suggestion of Sir Arthur Mitchell that the two identical practices might be due to perfectly independent origins generated in the human mind at two different epochs, is an important one in this instance. It is clearly just one of those practices which might be due to such a cause. There is nothing objectionable in it, on the contrary, it might be said to be rather a pretty idea than otherwise, and until we know the symbolism of the act in both cases, we cannot fairly say that a true survival of the hundredth power is presented to us. Until then we must, provisionally at all events, classify this modern custom as an independent development uninfluenced by the stone-age custom.

I now pass to the folk-tale. It is well known that the story of the Judgment of Solomon is also found in India, 
and I exhibit this evening a curious collection of Indian stories, which was sent me some years ago by Captain Temple, who has, I believe, never published them. The first of these stories, at the place marked, is the story of the Judgment of Solomon. Of course, it will be held by the borrowing school that one story came from the other, India, I believe, having the greatest number of votes on the question of the original home. But if we consider the story on its merits, why need we trouble ourselves about the possibility of its being borrowed? If it shows the wisdom of the Hebrew king, it also shows his savage barbarity; because it is certain that the denouement of the story rests upon the assumption that not only had he the power to kill the child by dividing it, but that he had the will and would have excrcised it. The point of such a story would be entirely lost if it were told of one of our own judges, and the distance betwcen the culture of Solomon's time and people and that of our own may be measured by this simple fact. But without the pale of civilisation such savagery as this is not singular; such a judgment as this is not confined to the typically highest wisdom, but extends to the typically lowest savage, because Mariner actually heard a similar judgment delivered by the savage king of the Tonga Islands to two of his tribe who were disputing the possession of a woman for wife, and they stopped the bloodshed which would actually have taken place just as the mother of the child did in Solomon's judgment. So that, given the necessary degree of savagery, the necessary indifference to the shedding of human blood, the necessary absolute power, and such a judgment would arise anywhere, and anywhen, and frequently.

Of course, along with the casualistic theory must be considered the possibility that the decadence of culture in any people would proceed back again to some of the stages from which it had previously developed. I advanced this argument some few years back in an article in the Archoeological Review, and it has since received the adhesion of 
Mr. C. G. Leland. I am certainly still inclined to think that it is one of the problems we must discuss in connection with continuity of custom and belief, but I do not think it will be found to prove so powerful a cause of continuity as the continuity of older races commingled with the higher.

In any case, it is clear that the continuity which is im. plied by the traditional survival of custom, belief, and myth, whether through the medium of the borrowing theory just propounded, or through continuity of the people who first brought the custom, belief, and myth into the country where they now are found, is an antagonistic hypothesis to spontaneous generation. Is it that my: examples of this latter, and Mr. Lang's examples grouped so ably in his preface to Grimm's stories, are limited in their nature and scope by mere accident, or is it that they are not fairly represented? If they are fairly represented, then the theory which they illustrate cannot account for one tithe of the survivals of ancient and purely savage thought in folk-lore. Pretty or innocent ideas associated with superstition and custom might be allowed to have originated with people living under a civilised culture; but nasty and disgusting customs cannot be so allowed, except after the most exceptional proofs, and we must fall back upon the hypothesis of continuity from the times when savage thought was represented by savage culture and savage people. I put this case strongly, because it seems to be so strangely. objected to by folk-lore students. Thus Mr. Jevons, in his beautiful edition of Plutarch's Roman Questions, puts the question point blank. "Mr. Gomme", he says, "argues that the fear of dead kindred was borrowed by the Aryans from the non-Aryan inhabitants of Europe. But why may noc the pro-ethnic Aryans, as well as the savages, have had a one stage of their development a fear of dead kindred ?" a question arising simply from the fact that $\mathrm{Mr}$. Jevond cannot bring himself to believe that the ancient Aryand ever borrowed any of the savage practices of the peoples 
they conquered. But, so far as I am concerned, I have never suggested that the Aryans have been wholesale borrowers of all the nasty and unpleasant customs and beliefs which are now found to survive amongst the nations who speak an Aryan language. On the contrary, I have raised the previous question-were not the ancient Aryan-speaking people settled down in the midst of, and over-lording, a non-Aryan aboriginal people? and is not the fear of dead kindred, as a cult with force enough at its back to be kept alive for centuries, more likely to have been derived from such aborigines than to have been derived from the sweepings of the Aryan mind? I confess the problem as put to me by Mr. Jevons and Mr. Lang seems singularly unfair to the Greeks, and I am on the side of the Greeks.

Once more I must confess to feelings of jealousy that folk-lore is not allowed to stand on its own footing. Mr. Jevons, in his brilliant study of Italian animism, stops just short of his true argument. On philological grounds only he starts off with the fallacious assumption that the ancient Italians were Aryans; he finds that the ancient Italians were in the animistic stage of culture, and he concludes that therefore the pro-ethnic Aryans were in that stage. This is an unholy alliance between philology and folk-lore, and, in the name of this Society, I forbid the banns. Finding the Italians to be in the animistic stage of culture, finding this to be opposed to the myth-making stage of Aryan culture, the conclusion would be that the Italians were in bulk non-Aryan, and surely I have only to suggest the Etruscan evidence to gain support for such a proposition even on philological grounds.

Well, then, it is clear that this principle of continuity needs much more study at our hands. At present we are a house divided against itself, but we are only at the beginning of our labours in this direction, and I foresee the time when a little more study of the principles of folk-lore, a little more attention to the minuter details which such a study necessitates, will once more bring us altogether in one vol. IV. 
school; just as most of us now, with one or two exceptions, against whom we delight to rub our ideas in this room and elsewhere, confessedly belong to the anthropological as distinguished from the literary school of folk-lore students.

The next principle of folk-lore research to which I shall direct your attention is the necessity for studying the environment of those who have brought down these traditional relics of earlier days. We who are students only of folk-lore, not collectors, we who are not partakers of the instincts which keep folk-lore alive, need to be perpetually reminded of the possibilities of the survival of crude traditional customs, beliefs, and myths among a peasantry living under the conditions of civilisation. It is so hard to believe that such things are; so difficult to understand that scientific knowledge, or, indeed, knowledge of any sort, beginning from above does not penetrate far down, and until lately could not have penetrated far down. We are always apt to think of others by our own standard, look at them through our own spectacles. But such a volume as The Denham Tracts, recently issued, ought, if anything can, to satisfy us that we do not know the people whose lore we are studying. The border chief who scorned property in land, and knew only property in his horse and sword, was not of the eighteenth century, he belonged to the eighth or ninth. For all that culture had done for him he might have come over with Hengist and Horsa. But that is just the point. If there are such survivals in flesh and blood, why need we doubt the survivals in custom, belief, and myth ? and we must go on collecting our flesh and blood evidences side by side with our other evidence. This evidence we get from all sorts of places. Among legal records and the doings of municipalities and manors we shall find plenty. Apart from such instances of municipal custom really being folk-lore, as Mr. Hartland in his Godiva study and Mr. Billson in his Easter Hare study have given to us, we meet with the evidences right and left of us. In a recently printed volume of the County 
Records of Middlesex - the county we are now meeting in -there is abundant evidence of the unadulterated beliefs of the people in the power of magical arts to do I don't know what, and this is what we want got ready for us in order that we may know who and what the people are and were whose folk-lore we are putting under the microscopewho, for instance, were the Cangick giants, a people who by tradition are said to have inhabited a certain district of Somersetshire, and of whom some measurements have been taken which would not, I am afraid, satisfy the scientific requirements of modern craniologists-the top of the skull of one of this giant race was said to have been $\mathrm{I}$ inch thick, and one of his teeth was 3 inches long above the roots, $3 \frac{1}{4}$ inches round, and weighed $3 \frac{1}{2}$ ounces. But these measurements are the work of a zealous antiquary of two centuries ago: the tradition is much older and far more correct.

And again, turning to something more than traditionto tradition and physical type commingled-there is the district of Barvas in Lewis, which by the Lewis people themselves is considered to be inhabited by a race distinct from those in the rest of the island-that is, they are dark, short, square, ugly, large-bellied, and with much cunning under a foolish exterior; they are said to be more backward than the rest, so that the "west side", which does not include Uig, is proverbially connected with dirt and slovenliness. In this part of Lewis alone remains the custory of leaving a hole in the thickness of the wall for a dormitory; it is plugged, of course, about three feet broad and one-and-a-half foot high, and long or deep enough for a man to lie in. Into this strange hole the person who would sleep gets in "feet foremost", sometimes by the help of a rope from above his head lying to the mouth of the hole, the hole or dormitory being four or five feet from the floor. I cannot but presume that this custom has a very remote origin, enabling us to form an idea of one of the domestic arrangements of the most ancient stone dwellings 
in our island, and probably lcading us, too, to the descendants of the ancient dwellcrs.

Next, there is the geographical distribution of folk-lore to consider. Dr. Kaarle Krohn has lately published a paper on this subject, in connection with the geographical distribution of Esthonian ballads, illustrated by a map. It is founded on an examination of the cnormous collections: of Esthonian folk-lore formed by different scholars, more especially by Pastor Hurt, among which no less than 30,000 articles consist of ballads.

The distribution of the tales throughout the provinces of Esthonia is mapped out in a very ingenious manner, of which the following key-plan may be given :

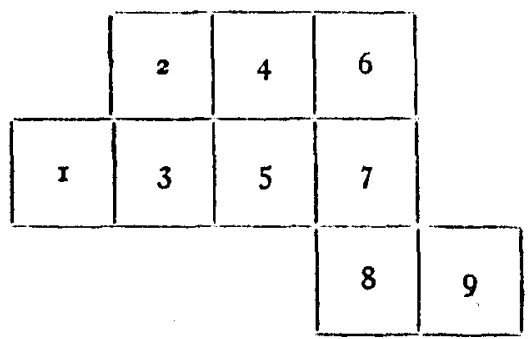

r. Oesel. 2. Wiek. 3. Pernau. 4. Harrien and Jerwen. 5. Fellin. 6. Wierland. 7. Dorpat. 8. Werro. 9. Pleskau.

As an example of the application of this table; I will take the ballad relating to the Gold and Silver Bride:

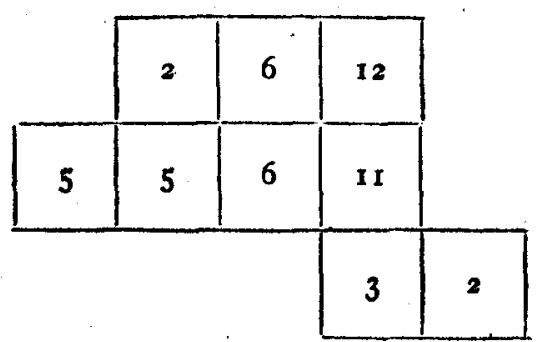


Of this story there are fifty-two variants obtained from the various provinces of Esthonia proper, and the numbers in each square indicate the number of variants obtained from each particular province.

A large map at the end of the paper shows the proportion of Esthonian ballad-literature in the adjoining countries, indicated by depth of red colour, and arrangement of red lines and circles. They preponderate in Esthonia proper, but fall off in Werro and Pleskau, and also along the south coast of the Gulf of Finland and the west coast of Lake Ladoga. North of Ladoga we find them still more or less numerous throughout a great part of Eastern Finland and the neighbouring parts of Russia, but throughout the greater part of Western Finland the Esthonian element appears to be almost entirely wanting.

It is obvious that the ingenious arrangements which Dr. Krohn has used in this paper may be applied in many other ways, and should not be overlooked by any serious student of folk-lore.

I shall trouble you with but one more principle of our science. If it were not that the subject is a serious one I should be inclined to term this the "human cussedness" principle. It is too often the case that in the science of man we neglect one most important factor, namely, human nature. We know how frequently it happens that, because we want a person, or a group of persons, to do one thing, they deliberately prefer to do something else; and when one is considering some universal or widespread practice of humanity-totemism, marriage, ancestor worship, ghost theory, or what not-it is not enough to study those people or those cases which illustrate the particular point in question, but it is necessary to study those cases which illustrate the exact opposite of that point.

We had during the session a very admirable study of marriage customs by $\mathrm{Mr}$. Hartland, and a point was raised as to the evidence of common residence on the history of human marriage. Mr. Westermarck, it is well known, in 
his important work on the subject, puts it that it is a prims tive rule that people living together in one residence do not: intermarry, and he gives many examples which certainlys tend to prove his point. But what about the cases, few only; it is true, where the opposite rule applies, as, for instance, amongst the Chukckes mentioned by Nordens, kiold? If these were studied I believe, they would by some special feature in their practices do much to explain their relationship to the opposite group of practices. They would explain how far changes in custom werc changes duo to social and economical development which might haves taken place under any conditions as to race, or whether. they were due to causes which were essentially bound up with race, such as, for instance, conquest and slavery. The change from exogamy to endogamy, from descent through females to descent through males, from marriage by capture to marriage by purchase, and other changes, which are now clearly defined in the history of human progress, are changes due more to economical causes than we are inclined to admit. And, if this is so, they might. happen, or have happened, with any people when the causes are in full operation.

But my point is that these contrasts in human sociology? want to be examined one against the other, want to be set down and stamped once for all with the stamp of scientific research, and not to be brought up against us at all sorts of times and occasions when their relevancy is not always so apparent as is the object of some adverse critic, whom you cannot answer because to do so would necessitate the writing of a separate treatise on a side issue. And then, when this has been accomplished, we. could estimate what, in the contrasts of human social forms and human thought, is due to sheer obstinacy-the taking up of a particular view because one class or one group of people take up another view. Somewhere in such an investigation would have to be considered the long-continued obstinacy with which mother-right has clung to the ideas 
of people. It has gone away from custom, except symbolically, in all European countries; but it has passed over to superstition, as, for instance, where, in the Merlin legend, the victim who alone can avert the magical opposition to the building of Vortigern's castle is a child who possesses a mother only; and in the modern popular superstition in Yorkshire, that a female who has never known her father possesses magical powers over disease. In these cases fatherhood is clearly at a discount, and its absence is a source of power. The question is, does it go back to times when descent was usually traced through females, and the marriage-system was not upon the system known to Celts, Teutons, and Northmen? or is it part and parcel of the same set of ideas indicated by the Somersetshire woman, who, when remonstrated with for marrying a disreputable man, replied: "Don't you see, sir, I had got so much washing I was forced to send it home, and if I hadn't had he I must have bought a donkey."

I venture to express the opinion on behalf of our Society that, if we were to cease work to-night, such a result as these principles represent may well stamp the last year's progress as a year of profit to the cause of science. But we are not going to stop work to-night, and I pass on to other phases of our year's doings.

I do not know whether any of you ever read evening newspapers, because, if so, it may have happened to you as it did to me, to read on the I Ith of October, in the year of grace one thousand eight hundred and ninety-two, a certain question in the pages of The Echo, a question which very nearly made me ill, and which will, I think, similarly affect most members of this Society, except perhaps my friend Dr. Gaster. It was as follows:

FAIRY TALES.-Will any reader tell me at what date "Cinderella" was written, and to what country its authorship belongs?-Felix.

In the presence of Miss Cox I am not going to answer that question, but $I$ quote it to show that there really do 
exist people who have not heard of the Folk-lore Society. Verily, the ways of ignorance are manifold, but they show at least that our work is not cnded.

I am not at all sure that the real grip of it can be said to have really begun. But it is in the beginning, at all events, and we shall want all our energies and all our resources to keep it properly in our own hands. We in England have no idea of organisation. We are content to do things as they come along, and when they come along, and where they come along. So that if at an Oriental Congress, or at a Royal Literary Society, or at some other gathering, whose objects had hitherto been distinctly not the objects of folk-lore, the subject of folk-lore crops up. forthwith it is moved, seconded, and resolved unanimously and with cheers, that a committee shall be appointed to investigate folk-lore! This is pure waste of energy, and waste of opportunity, and waste of power. All that is: folk-lore should come to us-we are the rightful owners of it ; and if individuals occasionally go to the "wrong shop", societies properly organised and careful of their own work and position should direct them to the right one. But $\mathbf{L}$ suppose it is hopeless in England to get people to be systematic in their labours and in the proper placing of their labours. And I fear that our own organisation as a a society is not so perfect that we can too quickly call out against our neighbours. The Annual Report this year contains suggestions which show that gradually we are waking up to our position; but I do hope, now that our prospects arc so bright, that we shall not only not lag behind, but shall be in the absolute forefront of all endeavours to bring about by co-operation what cannot be done without it.

For, after all, the great question for us as a society is, Can we yet declare a policy; a policy, I mean, which will guide our future work and shape our future organisation? Last year, at the close of my address, I touched only very slightly upon this subject, because I was not sure of my 
ground. This year there is no need, as it seems to me, to be so timid, because our policy is already indicated by the work we are doing. We are steadily sweeping the counties, one by one, and collecting into our pigeon-holes and into our printed material all that has been gathered by those good old people called antiquaries, who noted facts for their own sake, and left meanings and definitions alone. We should rearrange all these items of folk-lore in proper scientific order, and write the biography of each specific item, whether it be custom, belief, superstition, or myth. This seems to me to be the true policy of the future, and, if we have it steadily before us, I doubt not that we should find sufficient workers to co-operate loyally in effecting. each year something towards completing it. I know it will not be done except by many years of hard work and efficient organisation, continued without a break year after year. For myself I should be prepared to advocate at the Council a retrenchment of expenditure in some directions, where we may easily spend less, in favour of an increase of expenditure for the codification of British folk-lore. I believe that is our true policy from a scientific point of view : I believe it to be equally true from the point of view of expediency. Already the popular opinion of us and our work is changing, and changing rapidly. We are no longer considered to be harmless lunatics prettily chatting to each other about fairies, Mother Hubbard, and Little Riding Hood; it is a substantial testimony to this that, not long since, Mr. Leslie Stephen, who is not a member of our body, in a popular lecture alluded to the scientific problems and methods of folk-lore in tones of appreciation which his audience were quick to recognise ; and it is a gratifying compliment to our science and our Society that the Prime Minister-who, by-the-bye, has been one of our members from the beginning-has conferred upon one of our most recent members, Miss Lucy Garnett, the distinction of a civil list pension on account of her folk-lore work. 
There is much to indicate that folk-lore has a brilliant future before it as a philosophical as wcll as a scientific subject. This is, perhaps, too dangerous a topic to speak of now, and it is hardly yet within the range of practical folke lore objects. What we can say, however, without danger to individual opinions, is that no science dealing with man is quite perfect without the aid of folk-lore. Anthropology is not perfect without it, because folk-lore is the anthropo. logy of the civilised races, and without this complement the anthropology of barbarism and savagery is incomplete, and hence faulty.

The greatest problem of anthropology is the connection of modern with prehistoric man, and that this is still a burning question is shown by what Dr. Tylor only last year made the subject of his address at the Oriental Con? gress. But geology, archæology, philology, and the phys sical history of man cannot get on without the aid of folk-lore. To find a savage custom in a civilised country and to search out its counterpart among modern savagery: is a scientific act only when we have proved, as nearly at proof is possible, that the parallel is not representcd by one simple line drawn from civilisation to savagery, but by the three sides of a parallelogram, the connecting line between the two vertical ones being the horizon of prehist toric life.

G. L. GOMME. 